\title{
Distribution of Antibodies against Swine and Hong Kong Influenza Viruses among Pigs in 1977
}

\author{
Nobuhisa Yamane, Jiro Arikawa, Takato Odagiri, \\ Mitsuo Kumasaka* and Nakao Ishina \\ Department of Bacteriology, Tohohu University School of \\ Medicine, and*Sendai Municipal Institute of Health, Sendai \\ 980
}

\begin{abstract}
Yamane, N., Arlkawa, J., Odagiri, T., Kumasaka, M. and Ishida, N. Distribution of Antibodies against Swine and Hong Kong Influenza Viruses amony Pigs in 107\%. Tohoku J. exp. Med., 1978, 126 (2), 199-200 — The distribution of antibodies against swine and Hong Kong influenza viruses among hogs in Miyagi Prefecture was examined. Of 456 serum specimens collected since July 1977,12 were found to be positive against swine influenza virus and 6 against Hong Kong influenza virus. Such serological results reveal that swine and Hong Kong influenza viruses coexist in Japanese hogs and suggest that swine influenza virus reappeared in mid-1977. swine and Hong Kong influenza
\end{abstract}

As previously described in 1976, we were unable to find any positive sera against swine influenza virus-A/New Jersey/8/76(Hsw lN1) after the New Jersey event (Yamane et al. 1978). Since then we have continued serological surveillance of hogs in Miyagi Prefecture using swine and Hong Kong influenza viruses. We now describe the results obtained in $1977-78$.

Sera were collected at 3 weekly intervals from 6 months old hogs at the Sendai City Slaughterhouse. Collection began at the end of July 1977 and a total of 456 specimens have been taken up to the present time (January 1978). Pretreatment of swine sera to remove non-specific inhibitors and hemagglutinins was carried out as previously described (Yamane et al. 1978) and swine influenza virus, A/New Jersey/8/76 (Hswl N1), Hong Kong influenza virus, A/Victoria/3/75 (H3N2) and A/FM/1/47 (H1N1) were used in the hemagglutination inhibition (HI) tests.

Although all the swine sera were shown to be negative against the A/New Jersey/8/76 strain in 1976, 12 positive sera against this virus have appeared since the beginning of September 1977 (upper diagram of Fig. 1). As for Hong Kong influenza virus, A/Victoria/ $3 / 75$, the positive ratio was $6.5 \%$ in 1976 but, as shown in the lower diagram of Fig. 1 , this has now decreased to $1.3 \%$. The positive ratio to $\mathrm{A} / \mathrm{New}$ Jersey/8/76 was two times higher than that to A/Victoria/3/75.

After the appearance of a new type of influenza virus (H1N1) in Mainland China and Russia in 1977 , we included the A/FM/1/47 (H1Nl) strain in our sero-survey, but we could not find any positive sera.

In addition, we attempted to isolate influenza virus from 512 bronchial swabs taken from the autopsy lungs of hogs, but up to this time all the results have been negative.

The results obtained in our serological survey revealed that swine influenza virus, A/New Jersey/8/76-like strain, appeared among Japanese hogs in mid-1977 and seems to be spreading from herd to herd. Our observations have been confirmed by Dr. Shibata and his coworkers who were successful in the isolation of swine influenza strains closely

Received for publication, April 3, 1978. 

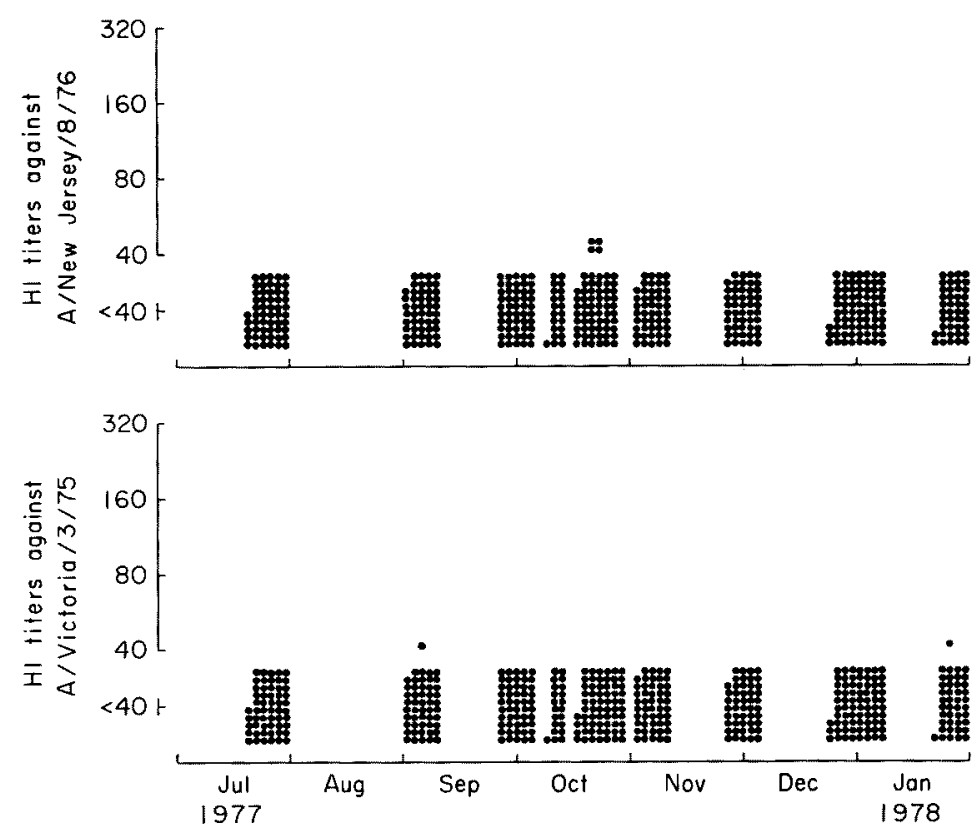

Fig. 1. Distribution of antibodies against A/New Jersey /8/76 and A/Victoria/3/75.

related to A/New Jersey/8/76 from hogs in Niigata Prefecture (personal communication from Dr. Shibata, Department of Bacteriology, Niigata University School of Medicine).

Also, it is apparent that the Hong Kong influenza virus coexists with this swine influenza virus at the same time at the same place. Under such a situation, genetic recombinations which result in the formation of new combination of envelope antigens (HswlN2 or $\mathrm{H} 3 \mathrm{Nl}$ ) and the exchange of the internal proteins may occur in nature. Taking this into consideration, it may now be necessary to analyse, in detail, the antigens of swine-origin influenza viruses.

\section{Acknowledgments}

We would like to thank Dr. J. Miura for his help to collect swine sera. This investigation was supported in part by grant from the Japanese Ministry of Health and Welfare.

\section{Reference}

1) Yamane, N., Sukeno, N. \& Ishida, N. (1978) Distribution of swine influenza antibody in Japan. Tohoku J. exp. Med., 125, 325-330. 